\title{
Euphemism And Political Discourse in the British Regional Press
}

\begin{abstract}
Politicians resort to euphemism as a "safe" way to deal with unpleasant subjects and criticize their opponents without giving a negative impression to their audiences. In this regard, it is my purpose to gain an insight into the way euphemism is used by politicians from Norfolk and Suffolk both at word and sentence level using a sample of the regional newspaper Eastern Daily Press, published in Norwich (UK). To this end, I will rely on the frameworks of critical-political discourse analysis (Van Dijk 1993, 1997; Wilson 2001), pragmatic theory, particularly politeness and facework (Brown and Levinson 1987), and Cognitive Metaphor Theory (Lakoff 1993). The results obtained reveal that euphemism plays an important role in the "self-promotion" of regional politicians, who employ euphemism - mostly by understatement, litotes and underspecification for a variety of purposes, namely sensitivity to audience concerns, avoidance of expressions that can be perceived to marginalize socially disadvantaged groups, polite criticism and mitigation - even concealment - of unsettling topics.
\end{abstract}

Key words

Euphemism; quasi-dysphemism; political discourse; politeness; face-saving strategies; PC language

\section{Introduction}

Language is a vital element in the daily life of politicians. To find the right kind of language and the right choice of words to address particular audiences is key not only to give a positive image of themselves but also of the parties they represent. We should not forget that political language ${ }^{1}$ is "purpose-oriented": politicians use language to achieve consensus, maintain support, influence people's 
thoughts and attract potential voters. In fact, political actors do not use language at random: their speeches and public comments are consciously and carefully constructed with a particular aim in mind.

The way politicians approach delicate or unpleasant subjects is of vital importance. It is the convention in politics to appear polite and sensitive to people's concerns while, at the same time, to try to win their favour or attack a political opponent. Political actors tend to avoid words or expressions that may have unpleasant associations in order not to give a negative impression to their audiences. To this end, they resort to euphemism, i.e., the process whereby a distasteful concept is stripped of its most inappropriate or offensive overtones, providing thus a "safe" way to deal with certain embarrassing topics without being politically incorrect or breaking a social convention. Granted that political language is, by definition, "polite" language use (i.e., characterized by conflict avoidance out of concern for the feelings of the audience), it is my contention that evasive vocabulary and other euphemistic strategies may reflect the politicians' sensitivity to audience concerns.

The focus of attention in this paper is on the positive (or at least non-negative) dimension of euphemism which arises out of concern for the addressees' feelings. There is also, however, a dark side to euphemism in the political sphere. When euphemism is purposefully used to conceal real facts from people, that is, when words are deliberately used to mislead and deceive, euphemism becomes a pernicious form of communication that Lutz $(1987,1999)$ calls doublespeak $^{2}$ and Allan and Burridge (1991: 13) refer to as deceptive euphemism. These types of euphemism perform two fundamentally different functions in discourse, namely to mitigate face threat (interpersonal function) and to project a self-interested version of reality (ideational function) that Luchtenberg (1985) refers to as veiling (verschleierns) and concealing (verhüllens) respectively.

My purpose here is therefore to gain an insight into the way euphemism is used by regional politicians from the counties of Norfolk and Suffolk using a sample of the regional newspaper Eastern Daily Press (henceforth EDP), edited in the city of Norwich (UK). To this end, I will rely on the theoretical framework of critical-political discourse analysis (Van Dijk 1993, 1997; Chilton and Schäffner 1997; Wilson 2001). In addition, the analysis of the metaphors encountered in the corpus will be embedded in Cognitive Metaphor Theory (Lakoff and Johnson 1980; Lakoff 1993) in line with studies which regard metaphor both as a cognitive and as a pragmatic phenomenon in the field of discourse analysis (MolekKozakowska 2014). In this paper, euphemism will be contextualized within pragmatic theory, particularly as an instantiation of facework. I will not only pay attention to lexis, the most surface level on language in which, as Rodríguez (1992: 38) notes, "the 'euphemized' or dissimulated object and its effects are easier to notice by the addressee". I will also consider euphemistic tactics that take place at sentence level.

Within the body of research on political discourse, euphemistic strategies have received considerable attention (Hoggart 1986; Lutz 1987, 1999; Rodríguez 
González 1992; Burridge 1998; Fraser 2009). To these studies we should add others devoted to "politically correct" (henceforth PC) language as a manifestation of euphemism in political discourse (Burridge 1998; Allan and Burridge 2006: chapter 4; Halmari 2011). However, to the best of my knowledge, no study so far has been devoted to the way local and regional politicians, usually unknown outside their city or region - in contrast to political elites - use euphemism in their speeches and public comments. I think that the modes of verbal attenuation used by politicians from the counties of Norfolk and Suffolk may be significantly different from those used by political elites insofar as local councillors and regional MPs are supposed to be more "visible", closer to the citizens and more concerned with their everyday worries than national politicians. In fact, by drawing on a corpus of Norfolk and Suffolk politicians' speeches and public comments, what constitutes politics in the present study is halfway between what Chilton and Schäffner (2002: 6) refer to as "institutional" politics (i.e., parliamentary debates, party conference speeches, etc.) and "everyday politics" (i.e., everyday issues and conflicts of a social and political nature). Therefore, as political euphemism may be expected to vary in these forms of political activity, the linguistic analysis of euphemism used by local and regional politicians undertaken here seems to be justified. ${ }^{3}$

The present paper is organized as follows. After briefly dealing with euphemism in the political sphere and its relationship with face concerns, I will consider the theoretical paradigms on which this study relies. Then I will present the corpus data and the methodology followed. Next, I will analyse the cases of euphemism (both at word and sentence level) encountered in the sample, which constitutes the core of the paper. The conclusions and final remarks will bring this study to an end.

\section{Political euphemism and face}

Prior to presenting the corpus data, it seems necessary to define the concept of euphemism in political discourse in relation to face concerns and the types of political euphemism existing. Allan and Burridge (2006) define euphemism (and its, roughly speaking, opposite dysphemism) by reference to the notion of face. They place X-phemistic (i.e., euphemistic and dysphemistic) processes on the basis of a continuum based upon the degree of face affront which is caused by the X-phemistic verbal expression: from an overt damage to the hearer's face or that of some third party involved in the communicative act (dysphemism) to maintaining the hearer's face in social interaction (euphemism). As these scholars explain, "dysphemism is a word or phrase with connotations that are offensive either about the denotatum and/or to people addressed or overhearing the utterance", whereas euphemism is an expression which tends to "avoid possible loss of face by the speaker, or also the hearer or some third party" (2006: 31-32). In this regard, euphemism can be defined as the use of mild and polite-sounding 
language to soften the potential face affront both to the speaker (for self-presentational purposes) and to the hearers (out of concern for their sensitivities).

From this definition it follows that political euphemism is closely tied to politeness ${ }^{4}$ (i.e., concern for the feelings of the interlocutor(s) according to the norms of social behaviour) through the notion of face (i.e., one's public self-image), initially proposed by Goffman (1967) and subsequently developed by Brown and Levinson (1987). Though face management compels language users to act in ways that preserve their public self images (and thus save face), face threatening acts may occur in communication, and when this happens people employ euphemism as a politeness strategy to mitigate face threat (Brown and Levinson 1987: 162-163; Crespo-Fernández 2005). In fact, euphemism constitutes a linguistic politeness marker which favours indirectness as a way to insure the mutual protection of face.

In this regard, following Allan and Burridge (1991, 2006), face concerns play a crucial role in understanding euphemism as a social phenomenon. Indeed, euphemistic use in political language responds to the politicians' need that their self-image be appreciated and approved of in the community, that is, to the desire of maintaining their positive face. ${ }^{5}$ Whether owing to pressures from the political parties they represent, or on account of the need to appear sensitive and considerate, the fact remains that verbal politeness plays an important role in the politician's strategy to win people's favour. In fact, in our Western contemporary societies, as Burridge (2010: 4) argues, taboos are closely linked with social organisation and therefore "social sanctions are placed on behaviour that is regarded as distasteful or at least impolite within a given social context". It goes without saying that this social sanction is precisely what politicians try to avoid through euphemism.

As an example of language used with a social purpose, political language is a breeding ground for euphemism and, in turn, euphemism stands out as a consubstantial element in political discourse. Political euphemism responds fundamentally to a social interdiction which has as its main aim to preserve the politicians' image and, in this way, give a good impression of themselves and the political groups they represent. ${ }^{6}$ And, we should not forget, in the political arena to cause a positive impression is of utmost importance. ${ }^{7}$ In this regard, political euphemism is determined by conventions of polite behaviour expected in public communication in accordance with Leech's Politeness Principle. ${ }^{8}$ This implies considering to what extent the use of euphemistic verbal expressions in communication, at both word and sentence level, is socially appropriate.

In order to analyse euphemism as a verbal strategy in political language, I adopt here a more comprehensive view than the one generally followed in the study of linguistic interdiction in which euphemism has been defined as a wordfor-word substitution (see, for example, McGlone et al. 2006: 261-263). In fact, to reduce the euphemistic process to a one-for-one lexical substitution would be to lose sight of the discursive euphemistic maneuvers that take place in political communication. In the present essay I therefore consider euphemism not only 
as a lexical process, but also as a verbal behaviour which politicians employ in the hope of softening the effect of what they really wish to communicate. In this regard, any lexical unit or verbal strategy which attempts to maintain one's positive face in communication can be said to be euphemistic. This implies to look at euphemism both at word level (word substitution, including figurative language) and at sentence level (euphemistic strategies beyond word choice).

Political euphemism can also be considered as a strategic device of PC language, i.e., "conformity to current beliefs about correctness in language and behaviour with regard to policies on sexism, racism, ageism, etc." (Burridge 2004: 206). Granted that politicians avoid displeasing groups of people, especially those who are most vulnerable in society (homeless and disabled people, sexual and ethnic minorities, etc.), they tend to avoid lexical labels deemed by many as inconsiderate and, obviously, impolite. It therefore comes as no surprise that euphemism is frequently used in political discourse in order not to appear insensitive towards disadvantaged groups and individuals. All euphemism communicates a particular attitude both to the addressee and to what is spoken about. However, PC-inspired language, as Burridge (1998: 66) notes, becomes "a political gesture - euphemism with attitude". That is, PC language communicates a political attitude on the part of the speaker towards the subject topic of the communication.

\section{Theoretical frames}

In studying the performance of politicians in the corpus, I will take a discourseanalytic approach to describe the data obtained. I will adopt the "social-theoretical" sense of discourse initially developed by Fairclough (1992). He offers a three-dimensional concept of discourse, i.e., discourse as a piece of text, discourse as an instance of discursive practice and discourse as an instance of social practice. His approach permits to assess the relationships between discursive and social change and relate properties of texts to social properties of discursive events as instances of social practice.

Following Fairclough's view of discourse, I will rely on critical-political discourse analysis as the theoretical frame to link the linguistic to the political. Critical-political discourse analysis is a field of discourse analysis which focuses on discourse in political forums (e.g. debates, speeches, press conferences, etc.) as the phenomenon of interest and critically studies the strategic use of linguistic patterns or keywords for achieving specific political aims (Chilton and Schäffner 1997: 219). According to Wilson (2001: 410), the goal of this type of research is "to seek out the ways in which language choice is manipulated for specific political effect".

Within this frame, language is understood as a social activity that is developed through the different functions it performs and through the structures used to perform these functions. In other words, political discourse can be considered as a form of political action which exerts social control in the socio-political 
context and ultimately reproduces and legitimates power through language (Van Dijk 1997: 11). From this perspective, language is seen both as social practice and as a mode of social action insofar as it is capable to have an impact on how social and political phenomena are perceived and on people's reactions to these phenomena. In this way, language contributes to determining people's behavior and is a social event having a direct influence in the context in which it is used. Given that politicians are able to influence their audiences through language, an analysis of the discursive strategies and structures which are involved in this process will tell us how this is done, as Van Dijk (1993: 259) claims. This approach to political discourse will allow me to analyse the way regional politicians try at all cost to win the favour of their audiences through euphemistic language and different types of evasive strategies.

As figurative language plays a role in political discourse (cf. Musolff 2004; Charteris-Black 2005; Hart 2008), I will also rely on Conceptual Metaphor Theory, initially developed by Lakoff and Johnson (1980) and redefined by later works, most notably Lakoff and Turner (1989) and Lakoff (1993). ${ }^{9}$ It is not my purpose here to review in depth this well-known framework. Suffice it to say that in this approach metaphor is defined as "a cross-domain mapping in the conceptual system" (Lakoff 1993: 203), that is, a mapping or set of conceptual correspondences from a source domain (i.e., the realm of the physical or more concrete reality) to a target domain (i.e., the concept we want to delimit and reify). Through these correspondences, metaphors stand as a means of understanding reality and making sense of our experience.

This theory also looks at metonymy as a cognitive strategy to conceptualize experience. Rather than as a figure of speech, metonymy is considered as a mental mechanism that underlies many aspects of human conceptualization: "Metonymic concepts allow us to conceptualize one thing by means of its relation to something else" (Lakoff and Johnson 1980: 35). In this way, metonymy is not merely seen as a device with a referential function but - the same as metaphor as a device capable of reasoning about reality in particular terms. The main difference between both processes lies in the fact that conceptual metonymies do not involve two domains, one of which more abstract than the other, in a relation of resemblance, as happens with metaphors. Metonymies operate within a single domain. They are cases of "one-correspondence mappings within a domain" (Ruiz de Mendoza Ibáñez 2000: 115) in a relation of contiguity whereby a part of a concept stands for the whole, the cause for the effect, the result for the action and so on. ${ }^{10}$

As language is considered here primarily as a social activity, the theoretical frames outlined in this section will allow us to gain an insight into the way euphemism fulfils its communicative and social goals in a sample of real language use. The analysis of euphemistic strategies - both at word and sentence level - presented here is embedded in theories which consider euphemism as the linguistic manifestation of social and interpersonal concerns. In order to explain the role of political euphemism in communication, certain pragmatic issues will also be 
addressed. As pointed out in Section 2, euphemism will be contextualized within pragmatic theory as an instantiation of facework within the more general frame of Brown and Levinson's politeness theory.

\section{Corpus and methodology}

Euphemism in general, and political euphemism in particular, is a context-sensitive phenomenon. A word or expression is not expected to be euphemistic (or dysphemistic) per se; rather, its attenuating (or offensive) quality considerably depends on the context in which it is used. In this regard, Allan and Burridge (1991: 4) argue that both euphemism and its counterpart dysphemism "are determined by the choice of expression within a given context: both the world spoken of, and the world spoken in" [in bold in the original]. As contextual issues play a crucial role in euphemism, this study is not based on isolated words, but on coherent and contextualized discourses excerpted from a sample of real language use.

As pointed out above, the language data for this study was excerpted from $E D P$, a regional newspaper covering information for Norfolk and north Suffolk published daily except on Sundays in Norwich. Founded in 1870 as a broadsheet, it moved to the compact (tabloid) format in the 1990s. Owned by Archant, a privately owned media company which has become one of the largest regional newspaper publishers in UK, EDP is considered to be non-partisan as far as political alignment is concerned. The choice for $E D P$ as a source of empirical data was not at random. This newspaper is a representative example of "regional serious press": it is regarded as a serious newspaper ${ }^{11}$ dealing with current political affairs and events and aimed at a spectrum of local and regional readers. Though $E D P$ is committed to regional issues, as already pointed out, it also covers, to a lesser extent, national and international news together with human interest stories and sports.

The corpus consists of 76 issues of $E D P$ published over a three-month period, from 1 February to 30 April 2014. I must make it clear that I have only included direct quotations of politicians' speeches and public comments as language data for the present study, as my purpose here is to analyse politicians' discourse, rather than the journalistic treatment of political issues in the production of news and commentary. To be precise, the corpus - which amounts to a total of 2,200 words - consists of 107 quotations distributed across the issues that constitute the sample in which 123 euphemistic items have been encountered. For the sake of privacy, the names of the politicians - mostly town and county councillors and regional MPs - have been omitted or hidden under the initials followed by an asterisk in the quotations used to illustrate the analysis.

The research methodology followed corresponds to the adoption of a "bottom-up" approach to explain the linguistic data obtained: first, selecting certain linguistic data at both word and sentence level; second, making generalizations given that data; and third, accounting for the meaning of linguistic items and their 
euphemistic function in discourse. To start with the data seems to be useful here, since, as Partington (2003: 27) points out, it is not always possible, or even desirable, to establish a priori the function of linguistic elements in discourse. This is especially true in a corpus of naturally-occurring language as the one used in the present study, given the unpredictability of linguistic behaviour in discourse. In order to select the data, I searched in the "local news" section of the newspapers in their entirety for euphemistic items in the comments of regional politicians. I thus started from the linguistic and described which strategic [euphemistic in this case] functions words and structures fulfil.

In order to identify the instances of euphemism in the sample, I looked for those cases in which verbal elements were used with the purpose of maintaining the communicator's and the addressee's positive face, in accordance with the view of euphemism outlined in Section 2. Once the cases of euphemism were found, I assigned the different modes of verbal attenuation to the categories of euphemism formation proposed by Allan and Burridge (1991) and by CrespoFernández (2007), both at word level (underspecification, understatement, litotes, overstatement, periphrasis, metaphor and metonymy) and at sentence level (passive voice, apologetic expressions, hedges and downtoners). Following Conceptual Metaphor Theory, I assigned the figurative language expressions to their corresponding conceptual networks as a prerequisite to explain the implications of the euphemistic units included in a particular domain. Then I tried to identify the intentions underlying the use of metaphors and metonymies in the corpus consulted. I did not focus on any specific topic, as my purpose here is not restricted to exploring euphemism in a particular field or taboo area, but to offer a general picture of the way euphemism is used in a sample of political language.

I should make it clear that the study presented here can make no claim to being complete or exhaustive. Indeed, the relatively small corpus consulted does not allow to reach valid conclusions in quantitative terms. My analysis is therefore mainly qualitative, following the tradition of critical discourse analysts, who have usually relied on small data samples (see, for example, Charteris-Black 2005). Furthermore, the limited scope of the present essay and the logical space limitations do not permit me to deal with the different types and examples of euphemism encountered in depth. Despite these limitations, I believe that the sample of euphemistic items analysed offers significant results regarding the functions of euphemism in the political life of the counties of Norfolk and Suffolk as shown in the regional press.

\section{Findings and discussion}

As indicated before, euphemism is a twofold phenomenon. It is not only a lexical process whereby distasteful words are replaced, but also a set of discursive tactics acting on verbal behaviour which does not conform to expectations and conventions of politeness. Therefore, in order to offer a fine-tuned analysis of political 
euphemism, it is necessary to explore the forms euphemism can take at both word and sentence level.

The linguistic devices employed for euphemism formation are shown in quantitative terms in Figure 1. It is to be noted that some euphemistic items fall at the same time into more than one category of euphemism formation, as I will explain in 5.1 .

Figure 1. Linguistic devices of euphemism in the corpus

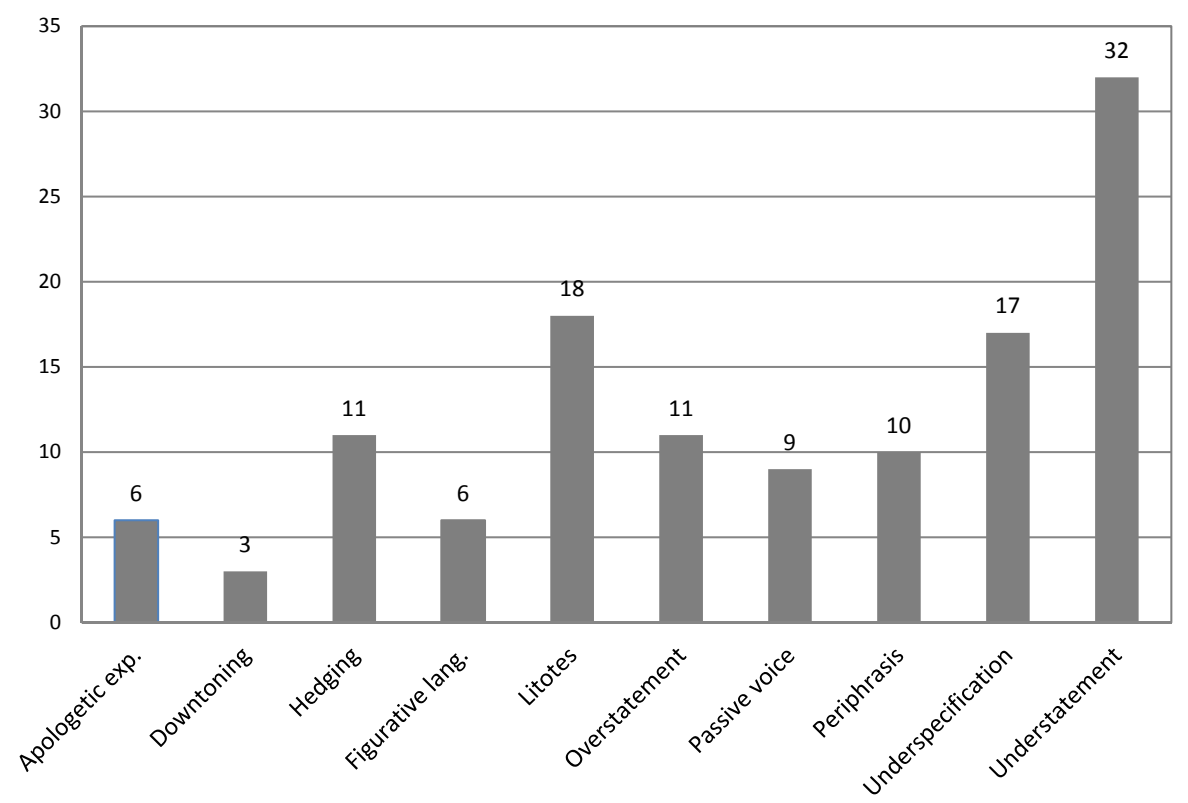

The first noticeable quality is that most euphemistic items are found at word level. Out of the 123 items encountered, only 29 occur at sentence level: hedges (11), passive voice (9), apologetic expressions (6) and downtoners (3). Concerning word level, the vast majority of devices of euphemism formation generate non-metaphorical items. Among them, understatement ranks the most frequent euphemistic resource (it records 32 occurrences) followed by litotes (18), underspecification (17), overstatement (11) and periphrasis (10). As shown in Figure 1, regional political discourse does not exploit figurative reasoning as a euphemistic resource in a significant way: metonymy is only responsible for four euphemistic items and metaphor just records two instances. 


\subsection{Euphemism at word level}

Lexis, the most surface level of language, is where the effects of euphemism are more clearly visible. Word choice, both at a metaphorical and non-metaphorical level, is indeed the most characteristic source of euphemism in the corpus. Let us first consider non-metaphorical word substitutions.

One of the lexical resources encountered is that of underspecification, i.e., the use of a general term which is required to be specified in its context of use to refer to a taboo subject and thus fulfil its euphemistic function (Allan 2012: 12). This device manifests in the corpus by means of vague and highly ambiguous words whereby politicians try to evade controversial topics. Given their generic nature, the euphemistic substitutes which derive from understatement are "general-for-specific" euphemisms (Allan and Burridge 1991: 17-18). Consider the following quotation:

(1) I know there are a few concerns ${ }^{12}$ about the scheme and I have some reservations myself, but we can go through this one step at a time. (March 28, p. 18)

By using generic terms like concerns and reservations, the politician avoids to specifically refer to the real problems that a new housing plan may cause in the town of Hertford. In fact, through these general-for-specific euphemistic items the politician deliberately avoids words with specific meanings in a strategy of "de-concretization" that fulfils an effective euphemistic goal. This de-concretization, as Sornig (1989: 106) puts it, "results in a deflation of referential (and connotational) context and therefore can serve as a semantic camouflage".

Underspecification is closely connected with a linguistic device of euphemism formation of a high occurrence in the corpus: understatement. Indeed, a generic term like concerns in (1) is halfway between both resources insofar as it presents an unpleasant topic as less serious than it really is in order to reduce its degree of potential face-affront. The term nuisance is another case in point of the interplay between both devices. By way of generalization and indeterminacy, nuisance refers in a subtle way to the damage caused by pot holes on the region's roads. Note how the use of cautious language in the form of the modal verb can contributes to minimize the dangerous effects of pot holes for the route users:

(2) Pot holes are a nuisance and they can be a danger, but they are unfortunately a fact of life. (April 22, p. 6)

The euphemistic terms in the two quotations above provide evidence for the crucial role ambiguity plays in euphemistic use. The contrast between the referent and its euphemistic materialisation at the lexical level is generally generated by ambiguity, which is considered an intrinsic feature of euphemistic naming (Chamizo Domínguez 2005: 10) capable to lead to a neutralization of the pejorative traits of the taboo referent in question. As Burridge (2012: 73) argues, ambiguity is a crucial feature of euphemism especially when its main motivation is to 
save face. For this reason, the use of terms involving a high degree of abstraction is particularly effective in political euphemism.

An interesting use of euphemistic understatement appears in the following quotation. The phrase error of judgement is a case of what Allan and Burridge (1991) call "deceptive" euphemism insofar as the politician seeks not so much to avoid being impolite as to lessen the impact on public opinion of the irregular voting record of a party colleague in the budget's debate:

(3) I tried to stop him voting a second time, so did the chap sitting next to him. It was a serious error of judgement on B.*'s part. (February 17, p. 15)

In spite of the use of the adjective serious qualifying the phrase error of judgement, the politician attempts to minimize the responsibility of the transgressor in the quotation above. The use of an adjective with negative connotations here does not mean that the phrase has lost its euphemistic force. Rather, to consider the politician's behaviour as serious is still milder than the fact that he has acted in a not very licit way during the voting procedure. After all, we should not forget that the attenuating quality of a word ultimately depends on the speaker's intention and the way it is used in a given context.

Understatement always leaves a room open for a more favourable interpretation of the distasteful topic being dealt with. In the following example the word suspended obviously has more positive connotations than "cut completely", as it implies a temporary - and not definitive - cessation of activities:

(4) This element was, in fact, suspended rather than cut completely so it has been identified the potential reinstatement should the funds become available (February 3, p. 15)

In the same vein, crimes and altercations committed in the clubland area of Norwich become issues of misconduct in quotation (5) below. By minimizing the adverse effects of antisocial behaviour, the politician creates an image of nightlife in the city as safe, or at least relatively safe. In this way, this euphemistic understatement falls on the side of concealment. There is a clear motivation behind euphemism here: the promotion of Norwich's clubland area as a source of economic revenue, even tourist appeal, for the city. Note how the generic term issues combines with understatement (misconduct) in order to mitigate the unpleasant reality that is hidden behind the euphemistic expression.

(5) They need power to deal with issues of misconduct [...]. The night time economy brings money into the city. We want to make sure people enjoy themselves in a safe environment. (March 15, p. 4)

Understatement does not only respond to a need for evasion and concealment, as seen in the quotations above. It is also a device speakers resort to when they 
need to imply more than they actually say. For this reason it is a useful resource of the euphemistic modality that I refer to as quasi-dysphemism, i.e., an axiological category including those items in which the euphemistic locution does not coincide with its dysphemistic illocutionary force in a communicative context and so provides a "safe ground" for the speaker's offensive intention (CrespoFernández 2007). A case of quasi-dysphemism or, in Allan and Burridge's (1991) terminology, "dysphemistic euphemism" appears in (6) through litotes. Litotes, one of the manifestations of understatement, mitigates the negative force of the utterance by expressing the affirmative through the denial of its opposite, which contributes to the intended euphemistic effect (Burridge 2012: 74). Note how a one-for-one euphemistic substitution (not making progress instead of failed) is used to criticize school staff:

(6) $\mathrm{We}^{13}$ have been working to support the school for some time; however the school has not been making fast enough progress. (February 4, p. 4)

Here the politician makes a critical remark in a socially acceptable way and hence with no threat posed to his public image. Litotes is used to keep verbal criticism within the limits of what one would conventionally consider polite behavior. In cases like these, Dynel (2009: 29) considers that politeness directly contributes to maintaining the speaker's positive face despite the verbal attack as a "redressive action taken to counterbalance the disruptive effects of face-threatening acts". In this way, as part of "politic verbal behavior" (Watts 2005), euphemism is a means which allows recourse to aggression in public discourse.

Litotes is not always used for polite derogation. In the following quotation not ideal substitutes a negatively-loaded adjective as a way of minimizing responsibility for the political decisions taken. The euphemism thus seems to conceal an unpleasant reality: lack of economic stability.

(7) The whole situation for us is not ideal, but it's a more positive outcome to have the money to put into the reserves than not to have it at all. (February 20, p. 17)

Euphemism can be also achieved by overstatement, that is, by upgrading a desirable feature of the referent. This device manifests in the phrase night time econo$m y$, used in (5) to highlight the positive aspects of night life activities (the money it brings into the city) and disregard the antisocial behaviour associated with it. Another case of euphemistic overstatement occurs in the following quotation in which maximize income refers to the expense of public money, a delicate subject to deal with in times of crisis and government cuts:

(8) Against a backdrop of central government cuts, the council wants to maximize income from the growth we will experience in the district. (February 18, p. 22) 
Note that in (7) and (8) items with openly favourable connotations like economy and maximize economy are used to embellish realities through contrast between the referents and their linguistic materialization, between what is said and what really is. This contrast provides the euphemistic basis of these items.

Periphrasis is another device used in the corpus to disguise unpleasant realities. Roundabout expressions are a means to avoid direct reference to something deemed unpleasant or potentially face-threatening. Many circumlocutions also imply understatement, that is, in the replacement of the word that might provoke discomfort the politician deliberately opts for alternatives of a significant less strength and severity. This is the case of the PC phrases those who are in a financial difficulty 'the poor' and families on lower incomes 'poor families' in quotations (9) and (10) below respectively. Strictly speaking, being in financial difficulty or having a low income is significantly less serious than living in poverty:

(9) We encourage people who are in a financial difficulty to make contact with us as soon as possible. (February 8, p. 5)

(10) I am pleased to see more families on lower incomes making the most of the help available once their child turns into two. (March 25, p. 37)

This type of periphrastic labels are regarded as socially acceptable ways to camouflage a harsh reality, poverty, and, in doing so, avoid discrimination against socially disadvantaged groups. Political actors resort to these type of circumlocutions in the hope of not appearing insensitive to vulnerable groups and individuals and thus safeguard their images. It is also worthy of note that in the euphemistic periphrases in (9) and (10), the language users have opted for referring to socially vulnerable people using postmodified nouns: people and families are postmodified by an adjectival relative clause and by a prepositional phrase respectively. This choice is not random. Following Halmari (2011), this pattern - that she refers to as "People first" approach - tends to favour PC-usage: the fact of putting the person before the problem is supposed to reflect a sensitive attitude to people living in poverty and, therefore, contributes to the civility that characterizes PC discourse. ${ }^{14}$

The use of euphemistic periphrases is not limited to PC-usage as a way to avoid discrimination against socially disadvantaged groups. In (11) a council member resorts to circumlocution as a means to avoid a very negatively loaded word, $i l$ legally, in the belief that this term may lead to doubts about the political integrity of those involved in the project of a waste incinerator for Norfolk. ${ }^{15}$

(11) There is not any evidence that any officer acted on anything other than what he thought was the best interest. (March 25, p. 37)

Many of the examples above show that poverty is a breeding ground for euphemism. Economic crisis has made poverty a particularly delicate topic, and its effects on people are not to be discussed openly. Even the term crisis itself is far 
from being neutral; indeed, recession has become a well-entrenched euphemistic alternative in public discourse to the negatively-loaded word crisis: ${ }^{16}$

(12) At a time when very few houses have been built because of the recession, in the last five years very few houses have been sold. (March 25, p. 27)

Let us now consider euphemistic figurative - metaphorical and metonymic - language. The only case of metaphorical euphemism encountered in the corpus is used to mitigate the taboo of death; more precisely, euthanasia:

(13) In my years as an MP, I have spoken to many patients [...] many of them have made the argument that when someone is suffering intolerably and when they are reaching the end of their life, they should be allowed to decide. (March 26, p. 15)

Here reaching the end of their life is a linguistic materialization of the conceptual metaphors LIFE IS A JOURNEY and DEATH IS THE END OF A JOURNEY. By virtue of this metaphor, mortality is seen in terms of our bodily experience of human domains through the SOURCE-PATH-GOAL image schema into which some of our experience is organized: "Complex events in general are also understood in terms of a source-path-goal schema; complex events have initial states (source), a sequence of intermediate stages (path) and a final stage (destination)" (Lakoff 1993: 275). By virtue of this schema, life is understood as a process with a starting, an end point and a time span. From this viewpoint, death is euphemistically conceptualized as the final stage of our lifespan by means of the metaphor DEATH IS THE END OF A JOURNEY. In the phrase reaching the end of their life the notions of time and movement play a crucial role. As Johnson (1987: 117) explains, "we have a metaphorical understanding of the passage of time based on movement along a physical path $[\ldots]$ toward some end point". And that conception of death as the final end point is the basis of euphemism in quotation (13) above.

Death is also subject to euphemism via the conceptualization DEATH IS A LOSS. This metaphor has a metonymic basis (THE EFFECTS OF DEATH STAND FOR DEATH) which focuses on one of the negative results of death. The conceptual basis of this mapping lies in the fact that life is perceived as a valuable object by virtue of the metaphor LIFE IS A PRECIOUS POSSESSION (Lakoff and Turner 1989: 29), and death is thus seen as the loss of this possession. ${ }^{17} \operatorname{In}(14)$ loss of life is a socially acceptable way to refer to death showing respect to the deceased and the surviving relatives. As Abbott (2010: 51) notes, this kind of phrases are instances of "respectful" euphemism in that they perform an "an act of social kindness":

(14) Any injury or loss of life is tragic. My heart-felt sympathy goes out to the relatives of the victim. There are lessons to be learned and improvements which must be made. (March 27, p. 5) 
Metonymy also plays a role in some of the cases of understatement detected in the corpus. The interplay between understatement and metonymy can be seen in the following quotation:

(15) People who come here are often people in debt [...] and because of this delay, people are not getting their money (March 1, p. 6)

Here the euphemistic label used as part of PC language people in debt is the result of two devices: understatement (the phrase minimizes the severity of the situation these people are living) and metonymy (it focuses on one of the effects of being in poverty in order to refer to the state of being poor under the metonymic principle THE EFFECTS OF POVERTY STAND FOR POVERTY).

\subsection{Euphemism at sentence level}

Apart from word choice, sentence construction significantly contributes to the politician's intended euphemistic effect and face-saving intention. A common strategy in the corpus is the choice of the passive construction whereby the agent is dissimulated and politicians distance themselves from the action and from the responsibilities which may derive from their wrong decisions. In this way, they attempt to minimize responsibility for actions taken. This happens in quotation (14) in which a Norfolk MP resorts to the passive voice ("lessons to be learned and improvements which must be made") instead of using the first person, which would have perhaps associated him with the car crash on the A47. In the same vein, the passive voice is used to evade direct responsibility, in this case for cutting social benefits:

(16) Benefits have had to be cut back but I think that the benefit pendulum has swung too far the other way. (March 1, p. 6)

In example (17) below a former West Norfolk councillor resorts to the passive voice with a different purpose. She publicly states that the voting procedure followed in the controversial proposal of King's Lynn incinerator (cf. Note 15) is the reason why she has quit Labour. She uses the passive voice as a quasi-dysphemistic strategy which permits her to condemn the voting system on the council while avoiding naming the politicians responsible for her resignation. In this way she criticizes both the Labour and the Conservative groups without fear of legal action against her:

(17) In the Labour group and the Conservative groups on the council [...] you are forced to vote in a certain way. [...] I'm against the proposal for an incinerator near King's Lynn, but at every meeting pressure was being put on me by the Labour group not to vote or speak about it. (February 28, p. 2) 
A similar case of socially acceptable criticism appears in (18). A county council cabinet member criticizes a political decision that kept him and his political fellows from a social event without explicitly mentioning those responsible for this decision. Unlike (17), the quasi-dysphemistic use of the passive voice seems to be motivated not so much for maintaining face as for avoiding legal responsibility.

(18) We weren't invited to today's event, which [...] was orchestrated as a decision to Mr. P*.'s visit to Norfolk. (February 1, p. 15)

In order to minimize the potential threat that distasteful subjects may pose, I have encountered indirect discursive strategies which I referred to elsewhere as mitigating apology expressions (Crespo-Fernández 2005). Apologetic expressions constitute previous or subsequent apologies or excuses regarding conflictive issues, and are therefore at the speaker's disposal to mitigate their face-affronting power (cf. Brown and Levinson 1987: 162-163). In the quotation below the expression "We had no option" justifies the decision taken by a Great Yarmouth MP on the voting about King's Lynn incinerator and thus acts as a kind of protective shield against possible criticism:

(19) On the basis of the officer's reports and the continuing reluctance of E.*P.* to release the outcome of the planning inquiry, we have no choice but to vote as per recommendation. (April 4, p. 6)

Though the sincerity of apologies cannot be taken for granted, apologetic expressions are effective devices of image restoration in political discourse in that they tend to minimize the politician's responsibility for mistakes and decision taking (Kampf 2009: 2258). In this sense, apologies are part of the politicians' attempts to reduce the risk of opposition and personal criticism as a sort of defensive strategy.

Let us finally consider the presence of hedges and downtoners in the corpus. Both devices are linguistic markers of deference that lessen the impact of unpleasant subjects on the audience and thus contribute to the politician's face needs. However, I will treat here hedges separately from downtoners as the mitigating function these devices perform is different. Hedges indicate the speaker's lack of complete commitment to absolute, categorical assertions; in this way, they attenuate the illocutionary force of the utterance (Fraser 2009: 201). By using cautious language in the form of expressions of modality - modal verbs (can, may) and probability adjectives (likely) - and epistemic lexical verbs (seem, appear), political actors tone down their statements in order to avoid sounding too dogmatic. This seems to be the case in quotation (20) below, in which the epistemic verb appears makes a critical remark more acceptable to the audience and hence weakens the full force of the speech act. Also of note is the use of the generic term concerns and the first person plural (cf. Note 13): 
(20) We have serious concerns about the budget and it appears that the administration is not planning properly for the long term and this is a long-term fix. (February 18, p. 4)

In the following example the epistemic adjective likely minimizes the negative impact of a beach closure. By means of this hedge, the politician avoids a categorical statement in the hope of giving the impression that this question remains open for a better solution:

(21) The parts of the beach that are presently closed would not be improved by the works and are likely to remain closed for some weeks to come. (April 12, p. 28)

Downtoners scale down the negative effect of the particular item they modify. Out of the different categories of downtoning terms and phrases proposed by Quirk et al. (1972: 452-458), compromisers (any sort of) and minimizers (a bit, a bit of) are used by regional politicians in order to tone down their statements. The most frequent downtoner in the corpus is the minimizer $a$ bit, which indicates a low position on a scale of degree (cf. Claridge and Kytö 2014). This minimizer functions as a degree modifier for predicate adjectives ( $a$ bit short of money, a bit unfair). Its prepositional variant $a$ bit of (a) modifies the semantics of nouns ( $a$ bit of criticism, a bit of a shame). The following quotation illustrates the euphemistic use of this downtoner:

(22) There has been a bit of criticism but I have got a broad back. As somebody who has got connections with Norfolk, I understand the depth of feeling there is and I see that as a plus rather than as a minus. (April 16, p. 6)

As seen in the three quotations above, there is an important feature of hedges and downtoners that contributes to their euphemistic effect. As happens with understatements and underspecifications, hedges and downtoners introduce an element of intentional vagueness and semantic indeterminacy (Fraser 2010: 25-27) which facilitates mitigation and face-saving when applied to political discourse.

\section{Concluding remarks}

What emerges from this piece of research is that Norfolk and Suffolk politicians resort to euphemism in order not to give a bad impression to their audiences when approaching delicate or controversial topics. Euphemism responds to an essential goal in political language: to safeguard the politicians' image and that of the political group they represent. Euphemism is thus primarily used for "representational" purposes, that is, through euphemism political actors construct a "safe" area to talk about embarrassing or distasteful topics without risk to appear insensitive 
or impolite. To this end, they resort to a wide range of euphemistic devices both at word and sentence level as a face-saving strategy. The overall frequency of occurrence of euphemism in the sample consulted (123 instances in a corpus of a total of 2,200 words) reflects that euphemism is a common phenomenon in the language used by local and regional politicians.

Lexis is where the effects of political euphemism are more clearly visible. Word choice, mostly non-metaphorical, is the most characteristic source of euphemistic reference in the corpus. Though the majority of euphemistic items occur at word level - most notably through understatement, litotes and underspecification - political euphemism cannot be regarded exclusively as a lexical process. It also operates at sentence level through a set of discursive tactics acting on verbal behaviour which does not conform to conventions of politeness. Passive constructions, hedges, downtoners and apologetic expressions are used by regional politicians as verbal strategies that facilitate the reference to controversial topics.

Political euphemism as shown here tends to generate a displacement effect with respect to the concept it designates which activates its mitigating and facesaving function in discourse. This displacement acts as a kind of camouflage that permits to reduce the communicative discomfort associated with unpleasant topics by avoiding a direct reference to them (cf. McGlone et al. 2006: 276) in favour of general terms (concerns), phrases with openly favourable connotations (maximize income), phrases focusing on the consequences of the event (in debt), terms which minimize the seriousness of an event (misconduct), etc. In this contrast between the literal and the euphemistic intended meaning, ambiguity plays a crucial role; in fact, many of the euphemistic devices discussed here introduce an element of intentional vagueness and semantic indeterminacy which facilitates the mitigation of face threat.

A total of 17 euphemistic items found in the corpus (which makes up 14\% of the total number of euphemistic forms encountered) are cases of PC language usage. In order to avoid displeasing disadvantaged social groups, namely those affected by the economic crisis, regional politicians resort to the softening effect of euphemism. Understatement has proven particularly effective for reducing the degree of severity of the situation of those living in poverty. Terms like vulnerable, periphrases such as in financial difficulty or labels like people in debt are examples of PC-language politicians employ in order not to appear insensitive towards those affected by the crisis. These euphemistic labels are a common way to cover-up those expressions that would bring to mind a harsh reality in an undeviating way.

The analysis also reveals that euphemism does not only perform a face-saving function which manifests in the use of words and expressions to cover-up distasteful realities. Euphemism also provides a "safe ground" for the speaker's offensive intention under the euphemistic modality of quasi-dysphemism. In addition, euphemism referring to such delicate topics as death and euthanasia seems to show a true concern and consideration for the feelings of those involved.

In summary, euphemism serves different purposes in the corpus of political language consulted: avoidance of discrimination to disadvantaged groups, 
concern for people's sensitivity, polite criticism and mitigation - even concealment - of unsettling topics. But whatever its communicative function, politicians from Norfolk and Suffolk adopt euphemism as a means of self-promotion within a more general politeness strategy of positive self-presentation.

\section{Notes}

$1 \quad$ Following Burkhardt (cited in Wodak 2012: 527), I understand by political language "all types of public, institutional and private talks on political issues, all types of texts typical of politics as well as the use of lexical and stylistic linguistic instruments characterizing talks about political contexts.

Lutz (1987: 21-22) defines doublespeak as "language which avoids or shifts responsibility, language which is at variance with its real or its purported meanings. It is language which conceals or prevents thought".

As an anonymous referee suggests, it would be interesting to undertake comparative research into the modes of verbal attenuation used by local and regional politicians and politicians in general. Such a comparative study is required to have a more comprehensive view of the nature and functions of euphemism in political discourse.

See Watts (2005: 44-50) for a comprehensive explanation of the term linguistic politeness. For an overview of the three classic politeness models (Lakoff's, Leech's and Brown and Levinson's), see Dynel (2009).

According to Brown and Levinson (1987: 13), the notion of face "consists of two kinds of desires ('face wants'): the desire to be unimpeded in one's actions (negative face), and the desire (in some respects) to be approved of (positive face)". As the political comments found in the corpus consulted do not really pose a threat to the addressee's desire for autonomy (i.e., negative face), I will focus on euphemism as a way to preserve the positive face or public self-image that politicians project in their public comments in their attempt to be positively regarded.

Common sense indicates that concern for people's sensitivities is not the main motivation of euphemism in politics. In fact, McGlone and Batchelor (2003) carried out an experiment in which they demonstrated that people tend to resort to euphemism because they need to make a positive impression on the audience, and thus avoid a threat to their own faces, rather than because of concern for their addressees' sensitivities.

7 Though beyond the scope of the paper, it is worth noting that euphemism is not the only verbal strategy at the politician's disposal to build a positive image. As an anonymous referee correctly observes, humour, "tough talk", jargon or "professional" language can also be used. Furthermore, very often paralinguistic features such as hand gestures and facial expressions are important aids in softening effects, as is voice intonation or pitch. These elements may even influence the choice of words used by the politician, depending on the medium that is going to be primarily used for conveying the speech.

Leech's (1983: 131-139), Politeness Principle is divided into six maxims (tact, generosity, approbation, modesty, agreement and sympathy). These maxims regulate a verbal behavior oriented towards avoiding conflict and minimizing any potential threat against the individual's social image in communication.

For recent redefinitions and improvements of the standard cognitive approach to metaphor, particularly those which look at the communicative impact of metaphors and their functions in culture and society, see Steen (2011) and Kövecses (2011).

10 Given the close links between metaphor and metonymy in real language use, I will consider them here as devices of figurative language that serve the purpose of conceptualizing reality in particular terms. For a comprehensive analysis of the interaction between metaphor and metonymy, see the volume edited by Dirven and Pörings (2003). 
11 I understand by serious newspapers those focused on serious journalism dealing with current political affairs and events, in contrast with less serious newspapers, generally known as "the popular press", that focus on celebrity coverage and sensationalist news reporting.

12 Hereafter the words and expressions that I want to highlight in the quotations provided as examples will appear in italics.

13 Though beyond the scope of this paper, it is worth mentioning that the first person plural we is used strategically by the politician in (6) as a means to distance himself from direct responsibility for political actions and thus avoid personal criticism. The same happens in (7) with the pronoun us. As demonstrated by Bull and Fetzer (2006), the pronominal choice made plays an important role in political rhetoric.

14 Halmari (2011: 837) makes an important distinction between the communicative functions of the postmodification and premodification patterns. She argues that whereas the former refers to socially vulnerable groups in a considerate way, the latter generally alludes to what she calls "undesirable" referents (e.g., "This retard killed his family.").

15 The Norfolk County Council's plan to build an incinerator near King's Lynn has been a source of political confrontation since permission was given in 2012. The project faced widespread opposition from regional MPs, local councils and residents and was finally cancelled at a cost of over $£ 30 \mathrm{~m}$ as financial penalty.

16 It is worth noting that the term crisis was systematically avoided during the first months of economic crisis in Spain, which had actually started in the first quarter of 2008. The Government spokesmen and the Prime Minister resorted to euphemistic alternatives (situación dificil 'difficult situation', crecimiento debilitado 'weakened growth', ajuste 'adjustment', and so on) to deliberately obscure the real economic situation of the country. It was not until July 2008 that José Luis Rodríguez, Spanish Prime Minister at that time, used the "forbidden" word in a rather peculiar way: "In this crisis, as you want me to call it, some people are not going through any difficulty" [my translation].

17 The conceptions of death as a concluding phase in human existence and as a loss of a valuable possession are common euphemistic means to refer to mortality in British and Spanish epitaphs (Crespo-Fernández 2013).

\section{References}

Abbot, Gerry (2010) "Dying and killing: Euphemism in current English". English Today 26 (4), $51-52$.

Allan, Keith (2012) "X-phemism and creativity". Lexis. E-Journal in English Lexicology 7, 5-42. $<$ http://lexis.univ-lyon3.fr>. Accessed 20 December 2013.

Allan, Keith and Kate Burridge (1991) Euphemism and Dysphemism. Language Used as Shield and Weapon. Oxford and New York: Oxford University Press.

Allan, Keith and Kate Burridge (2006) Forbidden Words. Taboo and the Censoring of Language. Cambridge: Cambridge University Press.

Brown, Peter and Stephen Levinson (1987) Politeness. Some Universals in Language Use. Cambridge: Cambridge University Press.

Bull, Peter and Anita Fetzer (2006) "Who are we and who are you? The strategic use of forms of address in political interviews". Text \& Talk 26 (1), 3-37.

Burridge, Kate (1998) "Euphemism with attitude: Politically charged language change". In: Schmid, Monika S., Jennifer R. Austin and Dieter Stein (eds.) Historical Linguistics. Amsterdam and Philadelphia: John Benjamins, 57-76.

Burridge, Kate (2004) Blooming English. Cambridge: Cambridge University Press.

Burridge, Kate (2010) "Linguistic cleanliness is next to godliness: Taboo and purism". English Today 26 (2), 3-13. 
Burridge, Kate (2012) "Euphemism and language change. The sixth and seventh ages". Lexis. EJournal in English Lexicology 7, 65-92. <http://lexis.univ-lyon3.fr>. Accessed 6 January 2014.

Chamizo Domínguez, Pedro (2005) "Some theses on euphemisms and dysphemisms". Studia Anglica Resoviensa 25, 9-16.

Charteris-Black, Jonathan (2005) Politicians and Rhetoric. The Persuasive Power of Metaphor. Basingstoke and New York: Palgrave Macmillan.

Chilton, Paul A. and Christina Schäffner (1997) "Discourse and Politics". In: Van Dijk, Teun A. (ed.) Discourse in Social Interaction. London: SAGE, 206-230.

Chilton, Paul A. and Christina Schäffner (2002) "Introduction. Themes and principles in the analysis of political discourse". In: Chilton, Paul A. and Christina Schäffner (eds.) Politics in Text and Talk. Analytic Approaches to Political Discourse. Amsterdam and Philadelphia: John Benjamins, 1-41.

Claridge, Claudia and Merja Kytö (2014) "I had lost sight of them then for a bit, but I went on pretty fast. Two degree modifiers in the Old Bailey Corpus". In: Taavitsainen, Irma, Andreas Jucker and Jukka Tuominen (eds.) Diachronic Corpus Pragmatics. Amsterdam and Philadelphia: John Benjamins, 29-54.

Crespo-Fernández, Eliecer (2005) "Euphemistic strategies in politeness and face concerns". Pragmalingüistica 13, 77-86.

Crespo-Fernández, Eliecer (2007) El eufemismo y el disfemismo. Alicante: Universidad.

Crespo-Fernández, Eliecer (2013) "Euphemistic metaphors in English and Spanish epitaphs. A comparative study". Atlantis. Journal of the Spanish Association of Anglo-American Studies 35 (2), 99-118.

Dirven, René and Rälf Pörings (eds.) (2003) Metaphor and Metonymy in Comparison and Contrast. Berlin: Mouton de Gruyter.

Dynel, Marta (2009) "Where cooperation meets politeness. Revisiting politeness models in view of the Gricean framework". Brno Studies in English 35 (1), 23-43.

Fairclough, Norman (1992) Discourse and Social Change. Oxford: Blackwell.

Fraser, Bruce (2009) "Hedging in political discourse: The 2007 Bush press conference". In: Cap, Piotr (ed.) Papers from the 2nd International Conference on Political Discourse, 201-213.

Fraser, Bruce (2010) "Pragmatic competence: The case of hedging". In: Waltenböck, Günther, Wiltrud Mihatsch and Stefan Schneider (eds.) New Approaches to Hedging. Bingley: Emerald Group, 15-34.

Goffman, Ervin (1967) Interaction Ritual: Essays on Face-to-Face Behaviour. New York: Double Day.

Halmari, Helena (2011) "Political correctness, euphemism and language change. The case of "People First". Journal of Pragmatics 43 (3), 828-840.

Hart, Christopher (2008) "Critical discourse analysis and metaphor: Toward a theoretical framework”. Critical Discourse Studies 5 (2), 91-106.

Hoggart, Simon (1986) "Politics". In: Enright, D. J. (ed.) Fair of Speech. The Uses of Euphemism. Oxford: Oxford University Press, 174-184.

Johnson, Mark (1987) The Body in the Mind. The Bodily Basis of Meaning, Imagination and Reason. Chicago: The University of Chicago Press.

Kampf, Zohar (2009) "Public (non-)apologies: The discourse of minimizing responsibility". Journal of Pragmatics 41 (11), 2257-2270.

Kövecses, Zoltán (2011) "Recent developments in metaphor theory: Are the new views rival ones?" Review of Cognitive Linguistics 9 (1), 11-25.

Lakoff, George (1993) [1979] “The Contemporary Theory of Metaphor”. In: Ortony, Andrew (ed.) Metaphor and Thought, 2nd ed. Cambridge: Cambridge University Press, 202-251.

Lakoff, George and Mark Johnson (1980) Metaphors We Live By. Chicago: The University of Chicago Press.

Lakoff, George and Mark Turner (1989) More than Cool Reason. A Field Guide to Poetic Metaphor. Chicago: The University of Chicago Press. 
Leech, Geoffrey (1983) Principles of Pragmatics. New York: Longman.

Luchtenberg, Sigrid (1985) Euphemismen im Heutigen Deutsch. Frankfurt-am-Main: Peter Lang. Lutz, William (1987) "Doublespeak at large". English Today 12, 21-24.

Lutz, William (1999) Doublespeak Defined: Cut through the Bull**** and Get the Point! New York: Harper Collins.

McGlone, Matthew S. and Jennifer A. Batchelor (2003) "Looking out for number one: Euphemism and face". Journal of Communication 53 (2), 251-264.

McGlone, Matthew S., Gary Beck and Abigail Pfiester (2006) "Contamination and camouflage in euphemisms". Communication Monographs 73 (3), 261-282.

Molek-Kozakowska, Katarzyna (2014) "Coercive metaphors in news headlines: A cognitive-pragmatic approach". Brno Studies in English 40 (1), 149-173.

Musolff, Andreas (2004) Metaphor and Political Discourse: Analogical Reasoning in Debates about Europe. Basingstoke and New York: Palgrave MacMillan.

Partington, Alan (2003) The Linguistics of Political Argument. The Spin-doctor and the Wolf-pack at the White House. London and New York: Routledge.

Quirk, Randolph, Sydney Greenbaum, Geoffrey Leech and Jan Svartvik (1972). A Grammar of Contemporary English. London: Longman.

Rodríguez González, Félix (1992) "Euphemism and political language”. UEA Papers in Linguistics $33,36-49$.

Ruiz de Mendoza Ibáñez, Francisco J. (2000) “The role of mappings and domains in understanding metonymy". In: Barcelona, Antonio (ed.) Metaphor and Metonymy at the Crossroads. Berlin and New York: Mouton de Gruyter, 109-132.

Sornig, Karl (1989) "Some remarks on linguistic strategies of persuasion”. In: Wodak, Ruth (ed.) Language, Power and Ideology. Amsterdam and Philadelphia: John Benjamins, 95-113.

Steen, Gerard (2011) "The Contemporary Theory of Metaphor. Now new and improved!" Review of Cognitive Linguistics 9 (1), 26-64.

Van Dijk, Teun A. (1993) "Principles of critical discourse analysis". Discourse \& Society 4 (2), 249-283.

Van Dijk, Teun A. (1997) "What is political discourse analysis?" In: Blommaert, Jan and Chris Bulcaen (eds.) Political Linguistics. Amsterdam and Philadelphia: John Benjamins, 11-52.

Wilson, John (2001) "Political discourse". In: Schiffrin, Deborah, Deborah Tannen and Heidi E. Hamilton (eds.) The Handbook of Discourse Analysis. Malden, MA: Blackwell, 398-416.

Watts, Richard (2005) [1992] "Linguistic politeness and politic verbal behaviour: Reconsidering claims for universality". In: Watts, Richard, Sachiko Ide and Konrad Ehlich (eds.) Politeness in Language (2nd ed.). Berlin: Mouton de Gruyter, 43-69.

Wodak, Ruth (2012) "Politics as usual. Investigating political discourse in action". In: Gee, James P. and Michael Handford (eds.) The Routledge Handbook of Discourse Analysis. Abingdon and New York: Routledge, 525-540.

Eliecer Crespo-Fernández is Lecturer in the Department of Modern Languages, University of Castile-La Mancha (Spain). His research interests include the semantic and pragmatic dimensions of euphemism and dysphemism in the areas of immigration, sex, and death, which he has approached through Cognitive Semantics and Discourse Analysis. He has recently focused on the persuasive nature of political language, with special attention to the role of metaphor. He has authored two books, edited two collective volumes and published a number of research articles in major, peerreviewed journals like Text \& Talk, Spanish in Context and Review of Cognitive Linguistics.

Address: Dr. Eliecer Crespo-Fernández. Facultad de Educación. Plaza de la Universidad 3, 02071 Albacete, Spain. [e-mail: Eliecer.Crespo@uclm.es]. 